\title{
PENGARUH PENAMBAHAN TAPE UBI UNGU DAN JAMUR KUPING TERHADAP DAYA TERIMA, OVERRUN DAN TITIK LELEH ES KRIM
}

\author{
Effect of Addition of Sweet Purple Tape and Jelly Mushroom to the Acceptability, \\ Overrun and Melting Points of Ice Cream
}

\author{
Miftachul Nur Jannah*, Rizka Mar'atus Sholichah, Arya Ulilalbab, Mirthasari Palupi ${ }^{1)}$ \\ Akademi Gizi Karya Husada Kediri Jl. Soekarno Hatta No. 7 Pare Kediri ${ }^{1)}$ \\ miftachul.nj@gmail.com
}

\begin{abstract}
A purple sweet potato were rich in carbohydrate classified as Low glycemix Index so that it can become a basic ingredient was maked a fermented sweet potato. The innovation of any variant product of ice cream could optimize the benefit of the purple sweet potato and jelly mushroom in order to increase public health. The purpose of this research was studied the influence of additional proportion of the fermented purple sweet potato and a jelly mushroom on acceptability, overrun and melting point of ice cream. This research was used the true experimental method complete random design with three treatments and replications. The treatment of the purple sweet potato $(50 \%, 40 \%, 30 \%)$, jelly mushroom $(30 \%, 40 \%, 50 \%)$, and skimmed milk (20\%). The influence of adding a fermented purple sweet potato and a jelly mushroom could be known by analyzed it with SPSS 17 with $\alpha 0.05$. For acceptance were used friedman rank, $\alpha 0.01$ for overrun test and melting point were used One Way Anova. If there are some differences, Duncan were used. The result of friedman rank on the parameter of color, aroma and taste did not gave an significantly. On the other hand, the parameter of texture gave an significantly. The result of One Way Anova were showed that there was significant on overrun and the melting point. It is advised to see the proportion of fermented purple sweet potato and jelly mushroom adding for a good acceptability, overrun and melting point based on the planned standard.
\end{abstract}

Keywords : ice cream, fermented purple sweet potato, jelly mushroom, acceptability, overrun, melting point

\begin{abstract}
ABSTRAK
Ubi jalar ungu mengandung karbohidrat tinggi yang tergolong Low glycemix Index sehingga dapat dijadikan sebagai bahan dasar pembuatan tape. Inovasi penganekaragaman produk es krim dapat mengoptimalkan manfaat ubi ungu dan jamur kuping untuk meningkatkan derajat kesehatan masyarakat. Tujuan dari penelitian ini adalah untuk mempelajari pengaruh proporsi penambahan tape ubi ungu dan jamur kuping terhadap daya terima, overrun dan titik leleh es krim. Penelitian ini menggunakan metode eksperimen serta menggunakan desain penelitian RAL (Rancanagan Acak Lengkap) dengan 3 perlakuan dan 3 replikasi. Dengan perlakuan tape ubi ungu $(50 \%, 40 \%, 30 \%)$, jamur kuping $(30 \%, 40 \%, 50 \%)$ dan susu skim $(20 \%)$ pada setiap perlakuan. Untuk mengetahui pengaruh penambahan tape ubi ungu dan jamur kuping dianalisa menggunakan SPSS 17 dengan $\alpha 0,05$. Untuk daya terima menggunakan uji friedman rank, $\alpha$ 0,01 untuk uji overrun dan titik leleh menggunkan uji One Way Anova, jika ada perbedaan kemudian dilanjut dengan uji Duncan. Hasil uji friedman rank terhadap parameter warna, aroma, dan rasa tidak berpengaruh signifikan, sedangkan untuk parameter tekstur berpengaruh secara signifikan. Hasil uji One Way Anova menunjukan ada pengaruh yang signifikan terhadap overrun dan titik leleh. Disarankan memperhatikan proporsi tape ubi ungu dan jamur kuping agar didapatkan daya terima yang baik, overrun dan titik leleh sesuai dengan standar.
\end{abstract}

Kata kunci : Es krim, tape ubi ungu, jamur kuping, daya terima, overrun, titik leleh 


\section{PENDAHULUAN}

Ubi jalar adalah tanaman herba yang tumbuh menjalar di dalam tanah dan menghasilkan umbi. Kandungan karbohidrat yang tinggi pada ubi jalar dapat dijadikan sebagai sumber kalori. Selain itu kandungan karbohidrat ubi jalar tergolong Low glycemix Index, yaitu tipe karbohidrat yang jika dikonsumsi tidak akan menaikkan kadar gula darah secara drastis. Serat pangan bermanfaat bagi keseimbangan flora usus dan bersifat prebiotik serta merangsang pertumbuhan bakteri baik yang terdapat pada usus, sehingga penyerapan zat gizi menjadi lebih baik (Murtiningsih dan Suyanti, 2011).

Jamur memiliki diversitas yang sangat tinggi dan memiliki ciri khas masing-masing dalam hal manfaatnya untuk kesehatan. Namun demikian, secara umum jamur pangan memiliki manfaat kesehatan yang hampir mirip dalam hal mencegah penyakit degeneratif. Beberapa bahan aktif yang terkandung sudah terbukti manfaatnya untuk kekebalan tubuh dan penyekit degeneratif (Tjokrokusumo, 2015). Manfaat jamur kuping ini telah diketahui sejak ratusan tahun lalu oleh bangsa Tionghoa. Lendir yang dihasilkan jamur kuping selama dimasak dapat menjadi pengental. Lendir jamur kuping dapat menonaktifkan atau menetralkan kolesterol (Purnomowati, 2015).

Tape merupakan makanan khas Indonesia yang dihasilkan dari proses fermentasi bahan pangan karbohidrat. Prinsip dasar proses fermentasi adalah degradasi komponen pati menjadi dekstrin dan glukosa, selanjutnya glukosa diubah menjadi alkohol atau asam sehingga hasil dari proses fermentasi terasa sedikit asam dan sedikit manis. Pada umumnya tape terbuat dari bahan pangan singkong dan ketan (Marminah, 2012). Tape memiliki keunggulan yaitu meningkatkan kandungan vitamin $\mathrm{B}_{1}$ (Thiamin) hingga tiga kali lipat. Vitamin ini diperlukan oleh sistem syaraf, sel otot, dan sistem pencernaan agar dapat berfungsi dengan baik. Karena mengandung berbagai macam bakteri baik yang aman dikonsumsi, tape dapat digolongkan sebagai sumber prebiotik bagi tubuh. Cairan tape diketahui mengandung bakteri asam laktat \pm 1 juta per mililiter gramnya. Produk fermentasi dapat memberikan efek menyehatkan tubuh, terutama sistem pencernaan, karena meningkatkan jumlah bakteri baik dalam tubuh dan mengurangi jumlah bakteri jahat. Kelebihan lain dari tape adalah kemampuannya mengikat dan mengeluarkan aflatoksin dari tubuh. Aflatoksin merupakan zat toksik atau racun yang dihasilkan oleh kapang, terutama Aspergilus flavus (Asnawi, dkk, 2013).

Kedua bahan pangan tape ubi ungu dan jamur kuping memiliki kandungan gizi yang baik untuk kesehatan sehingga adanya inovasi penganekaragaman produk pangan diperlukan agar masyarakat dapat merasakan manfaatnya dengan optimal. Seperti halnya penganekaragaman pangan dengan menggabungkan kedua bahan pangan ini pada produk es krim. Es krim merupakan makanan beku, hidangan penutup yang biasanya terbuat dari produk susu dan bahan tambahan yang membantu dalam proses pembuatan es krim.

Dari hasil uji pendahuluan yang telah dilakukan didapatkan hasil dengan 3 perlakuan dimana PI susu skim : tape ubi ungu : jamur kuping (20\% : 50\% : 30\%), perlakuan PII susu skim : tape ubi ungu : jamur kuping (20\%: $30 \%$ : 50\%), dan perlakuan PIII yaitu menggunakan 100\% susu skim tanpa penambahan tape ubi ungu dan jamur kuping. Berdasarkan hasil uji organoleptik diperoleh hasil penilaian dari 10 panelis menyatakan sebanyak $50 \%$ menyukai es krim kontrol (100\% susu skim) dan sebanyak $50 \%$ menyukai es krim dengan penambahan tape ubi ungu dan jamur kuping. Dari 50\% panelis yang menyukai es krim dengan penambahan tape ubi ungu dan jamur kuping sebanyak 30\% menyukai es krim pada PII yaitu dengan proporsi susu skim : tape ubi ungu : jamur kuping (20\% : $30 \%$ : 50\%). Sebanyak $20 \%$ menyukai es krim pada PI yaitu dengan proporsi susu skim : tape ubi ungu : jamur kuping (20\% : $50 \%$ : 30\%). Dari hasil uji pendahuluan 
tersebut, tape ubi ungu dan jamur kuping berpotensi untuk dijadikan bahan subtitusi dalam pembuatan es krim.

Penelitian ini bertujuan untuk menganalisis pengaruh penambahan tape ubi ungu dan jamur kuping terhadap daya terima, overrun dan titik leleh pada es krim.

\section{BAHAN DAN METODE}

\section{Bahan}

Bahan baku yang digunakan untuk pembuatan es krim tape ubi ungu dan jamur kuping adalah ubi ungu yang diperoleh dari
Kota Blitar, jamur kuping, susu skim, gula pasir, garam, telur didapatkan dari pasar tradisional Pare Kediri, dan whipping cream didapatkan dari Hypermart Kediri.

\section{Alat}

Peralatan yang digunakan untuk pembuatan es krim tape ubi ungu dan jamur kuping yaitu panci, spatula, wadah plastik, mixer, freezer, sendok makan, kompor gas, timbangan bahan makanan, baskom, pisau dan telenan.

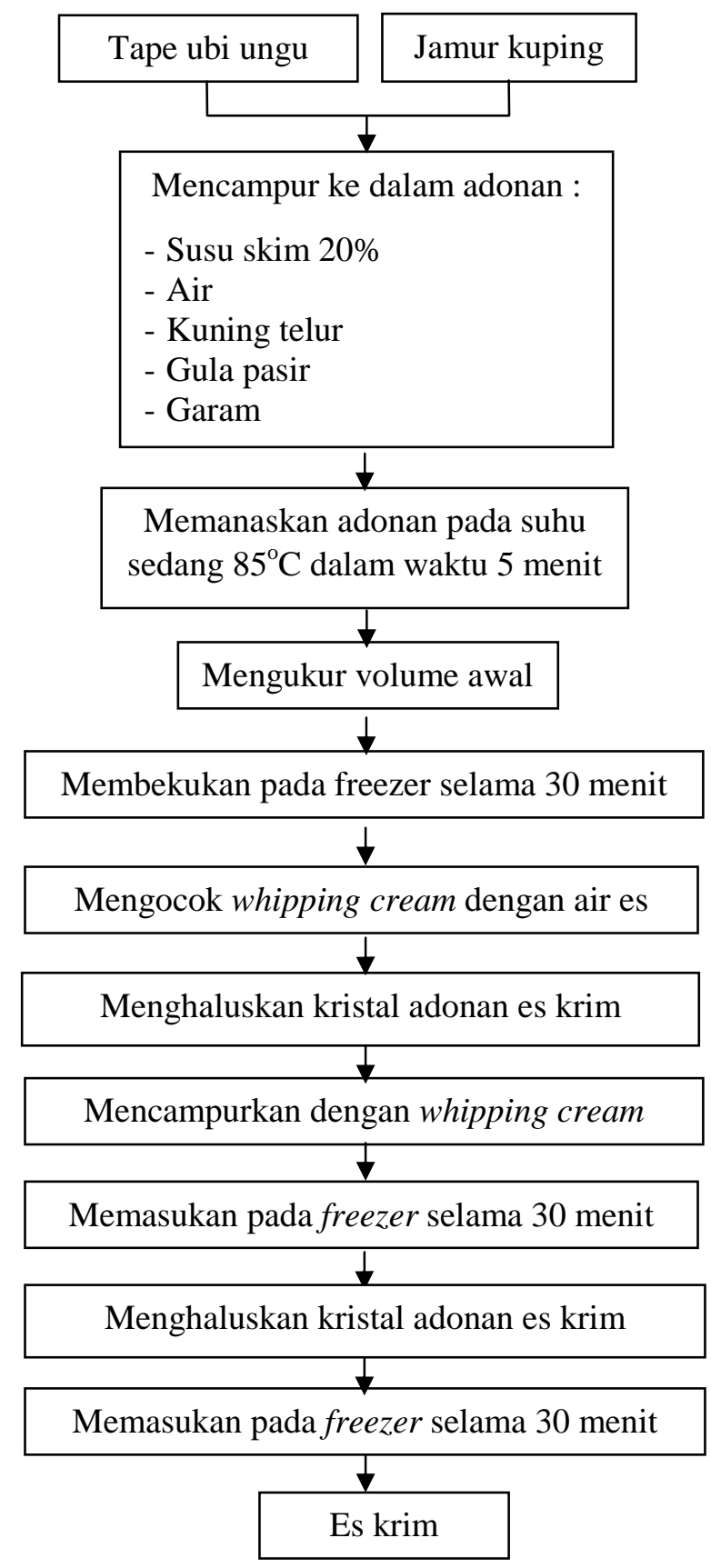

Gambar 1. Prosedur Pembuatan Es Krim Tape Ubi Ungu dan Jamur Kuping 


\section{Metode}

Metode penelitian ini menggunakan metode eksperimen, dengan design penelitian Rancangan Acak Lengkap (RAL) dengan 3 perlakuan dan 3 replikasi. Perlakuan yang digunakan memiliki 3 perbandingan susu skim : tape ubi ungu : jamur kuping (PI (20\% : 50\% : 30\%), PII (20\%: $40 \%: 40 \%)$, PIII (20\% : 30\% : 50\%) ). Pengujian daya terima, overrun dan titik leleh telah dilaksanakan pada tanggal $07 \mathrm{Mei}$ 2016. Data yang diperoleh dianalisis menggunakan SPSS versi 17. Pengujian daya terima dianalisis menggunakan uji Friedman Rank. Pengujian overrun dan titik leleh dianalisis mengunakan uji One Way Anova dan dilanjut dengan uji Duncan.

\section{HASIL DAN PEMBAHASAN}

\section{Daya Terima}

\section{Warna}

Nilai rerata yang didapatkan, diketahui bahwa nilai rerata paling tinggi yaitu pada PIII (susu skim 20\% : tape ubi ungu 30\% : jamur kuping 50\%) yaitu sebesar 3,49. Hasil analisis menggunakan uji friedman rank terhadap warna es krim tape ubi ungu dan jamur kuping didapatkan nilai sig $=0,10>\alpha$ $=0,05$ maka $\mathrm{H} 0$ diterima yang berarti proporsi penambahan tape ubi ungu dan jamur kuping tidak berpengaruh terhadap warna yang dihasilkan. Sedangkan untuk persentase daya terima panelis terhadap produk tersaji dalam gambar 2 .

Aspek penilaian warna pada PI (susu skim 20\% : tape ubi ungu 50\% : jamur kuping 30\%) dan PII (susu skim 20\% : tape ubi ungu $40 \%$ : jamur kuping 40\%) memperoleh persentase yang sama yaitu $75,6 \%$ dengan warna yang hampir sama yaitu ungu muda keputih-putihan. Pada PIII (susu skim 20\% : tape ubi ungu 30\% : jamur kuping 50\%) menghasilkan persentase $77,4 \%$ dengan warna produk keputihputihan. Dari ketiga perlakuan tersebut panelis cenderung lebih menyukai produk PIII (susu skim 20\% : tape ubi ungu 30\% : jamur kuping 50\%), hal ini dikarenakan warna antosianin dari tape ubi ungu tidak menghasilkan warna ungu yang terlalu dominan pada es krim sehingga warna es krim akan semakin berwarna putih susu seperti es krim pada umumnya, sehingga daya terima panelis meningkat pada perlakuan es krim dengan proporsi penambahan tape ubi ungu yang sedikit.

Tabel 1. Rerata tingkat kesukaan panelis terhadap warna es krim tape ubi ungu dan jamur kuping

\begin{tabular}{cccc}
\hline & \multicolumn{3}{c}{ Perlakuan Produk } \\
\cline { 2 - 4 } Replikasi & \multicolumn{3}{c}{ Susu Skim (\%) : Tape Ubi Ungu (\%) : Jamur Kuping(\%) } \\
\cline { 2 - 4 } & PI & PII & PIII \\
& $(20: 50: 30)$ & $(20: 40: 40)$ & $(20: 30: 50)$ \\
\hline I & 3,43 & 3,4 & 3,47 \\
II & 3,46 & 3,4 & 3,67 \\
III & 3,43 & 3,5 & 3,3 \\
\hline$\Sigma$ & 10,32 & 10,3 & 10,44 \\
\hline$\Sigma$ & $3,44 \pm 0,55$ & $3,43 \pm 0,55$ & $3,49 \pm 0,51$ \\
\hline
\end{tabular}




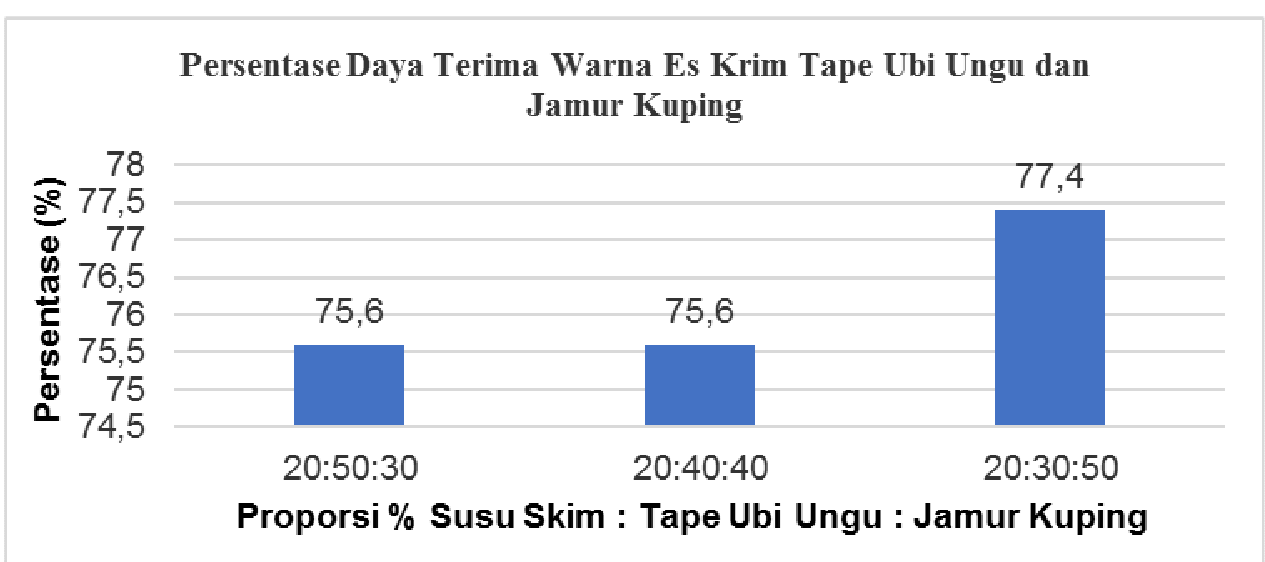

Gambar 2. Persentase daya terima panelis terhadap aroma es krim tape ubi ungu dan jamur kuping.

Menurut Husna, dkk (2013) pada penelitian kandungan antosianin dan aktivitas antioksidan ubi jalar ungu segar dan produk olahannya mengungkapkan bahwa kadar antosianin pada ubi jalar ungu berkurang karena adanya pemanasan yaitu pada saat proses pengukusan. Antosianin merupakan senyawa yang larut air, terjadinya kontak antara ubi ungu dan uap air dapat mengurangi kadar antosianin. Hal ini juga sesuai dengan pernyataan $\mathrm{H}$. Budhiarto bahwa lama pengukusan ubi jalar ungu 1525 menit menurunkan nilai rata-rata total antosianin.

\section{Aroma}

Aspek penilaian aroma pada PI (susu skim 20\% : tape ubi ungu 50\% : jamur kuping 30\%) menghasilkan persentase $68,4 \%$ dengan aroma produk lebih dominan tape ubi ungu daripada jamur kuping. Sedangkan PII (susu skim 20\% : tape ubi ungu $40 \%$ : jamur kuping 40\%) menghasilkan nilai persentase $77,4 \%$ dengan aroma produk yang kuat pada masingmasing bahan. Pada PIII (susu skim 20\% : tape ubi ungu 30\% : jamur kuping 50\%) aroma produk lebih dominan jamur kuping daripada tape ubi ungu. Dari ketiga perlakuan panelis cenderung lebih menyukai produk dengan PII (susu skim 20\% : tape ubi ungu 40\% : jamur kuping 40\%), hal ini dikarenakan penambahan tape ubi ungu dan jamur kuping dengan proporsi yang sama menghasilkan aroma yang dominan pada masing-masing bahan. Aroma asam dari tape ubi ungu dan aroma jamur kuping yang khas lebih disukai oleh panelis. Semakin tidak dominan penambahan tape ubi ungu dan jamur kuping pada es krim, daya terima panelis semakin menurun terhadap parameter aroma. Menurut penelitian Filiyanti, dkk (2013), proporsi penambahan ubi ungu mempengaruhi aroma dari es krim. Semakin banyak proporsi penambahan ubi ungu maka aroma yang dihasilkan juga semakin kuat

Tabel 2. Rerata tingkat kesukaan panelis terhadap aroma es krim tape ubi ungu dan jamur kuping

\begin{tabular}{cccc}
\hline & \multicolumn{3}{c}{ Perlakuan Produk } \\
\cline { 2 - 4 } Replikasi & \multicolumn{3}{c}{ Susu Skim (\%) : Tape Ubi Ungu (\%) : Jamur Kuping(\%) } \\
\cline { 2 - 4 } & PI & PII & PIII \\
& $(20: 50: 30)$ & $(20: 40: 40)$ & 3,43 \\
I & 3,13 & 3,3 & 3,37 \\
II & 3,2 & 3,2 & 2,97 \\
III & 3,3 & 9,93 & 9,44 \\
\hline$\Sigma$ & 9,63 & $3,31 \pm 0,44$ & $3,14 \pm 0,58$ \\
\hline$\Sigma$ & $3,21 \pm 0,50$ & 78
\end{tabular}




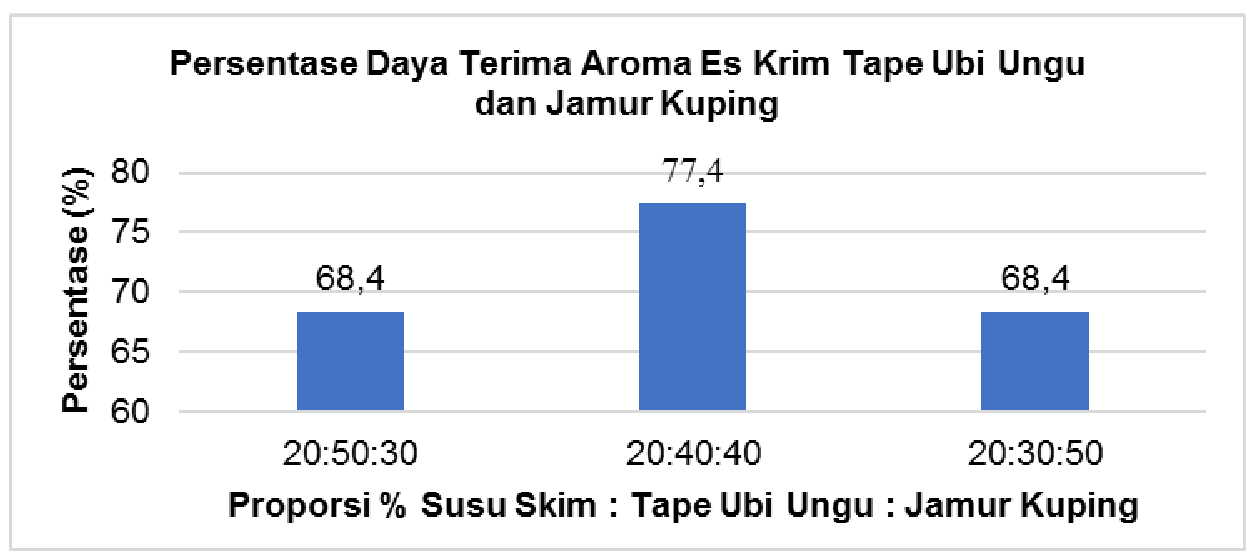

Gambar 3. Persentase daya terima panelis terhadap aroma es krim tape ubi ungu dan jamur kuping

\section{Rasa}

Tabel 3. Rerata tingkat kesukaan panelis terhadap rasa es krim tape ubi ungu dan jamur kuping

\begin{tabular}{cccc}
\hline & \multicolumn{3}{c}{ Perlakuan Produk } \\
\cline { 2 - 4 } Replikasi & \multicolumn{3}{c}{ Susu Skim $(\%):$ Tape Ubi Ungu (\%) : Jamur Kuping(\%) } \\
\cline { 2 - 4 } & PI & PII & PIII \\
& $(20: 50: 30)$ & $(20: 40: 40)$ & $(20: 30: 50)$ \\
\hline I & 3,37 & 3,43 & 3,4 \\
II & 3,4 & 3,3 & 3,43 \\
III & 3,27 & 3,53 & 2,97 \\
\hline$\Sigma$ & 10,4 & 10,26 & 9,8 \\
\hline$\Sigma$ & $3,34 \pm 0,76$ & $3,42 \pm 0,76$ & $3,27 \pm 0,73$ \\
\hline
\end{tabular}

Nilai rerata yang didapatkan, diketahui bahwa nilai rerata paling tinggi merupakan rerata produk PII (susu skim 20\% : tape ubi ungu $40 \%$ : jamur kuping $40 \%$ ) dengan nilai rerata sebesar 3,42.

Hasil analisis menggunakan uji friedman rank terhadap parameter rasa es krim tape ubi ungu dan jamur kuping didapatkan nilai sig $=0,08>\alpha=0,05$ maka $\mathrm{H}_{0}$ diterima yang berarti proporsi penambahan tape ubi ungu dan jamur kuping tidak berpengaruh terhadap rasa yang dihasilkan. Sedangkan untuk persentase daya terima panelis terhadap produk tersaji dalam gambar 4.

Aspek penilaian rasa pada PI (susu skim 20\% : tape ubi ungu 50\% : jamur kuping 30\%) menghasilkan persentase $69,3 \%$ dengan rasa produk lebih asam karena dominan tape ubi ungu daripada jamur kuping. Sedangkan pada PII (susu skim 20\% : tape ubi ungu 40\% : jamur kuping 40\%) menghasilkan nilai persentase $72 \%$ dengan rasa yang lebih kuat pada masing-masing bahan. Pada PIII (susu skim 20\% : tape ubi ungu $30 \%$ : jamur kuping $50 \%$ ) menghasilkan persentase $62,1 \%$ dengan rasa produk lebih dominan jamur kuping daripada tape ubi ungu. Dari ketiga perlakuan panelis cenderung lebih menyukai produk PII (susu skim 20\% : tape ubi ungu $40 \%$ : jamur kuping 40\%), hal ini dikarenakan penambahan tape ubi ungu dan jamur kuping dengan proporsi yang sama menghasilkan rasa yang dominan pada masing-masing bahan. Semakin tidak dominan penambahan tape ubi ungu dan jamur kuping pada es krim, daya terima panelis semakin menurun terhadap parameter rasa. Menurut penelitian Filiyanti, dkk (2013), jumlah ubi ungu yang ditambahkan sedikit banyak mempengaruhi rasa dari es krim. Semakin banyak penambahan ubi ungu maka rasa yang dihasilkan juga semakin kuat. 


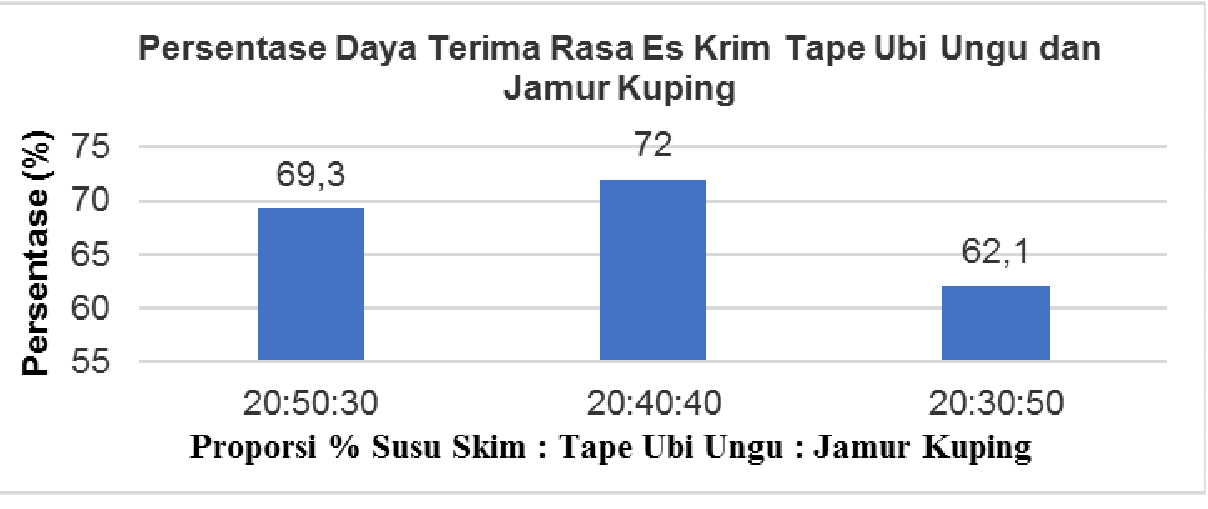

Gambar 4. Persentase daya terima panelis terhadap rasa es krim tape ubi ungu dan jamur kuping

\section{Tekstur}

Tabel 4. Rerata tingkat kesukaan panelis terhadap tekstur es krim tape ubi ungu dan jamur kuping

\begin{tabular}{cccc}
\hline & \multicolumn{3}{c}{ Perlakuan Produk } \\
\cline { 2 - 4 } Replikasi & \multicolumn{3}{c}{ Susu Skim (\%) : Tape Ubi Ungu (\%) Jamur Kuping(\%) } \\
\cline { 2 - 4 } & PI & PII & PIII \\
& $(20: 50: 30)$ & $(20: 40: 40)$ & $(20: 30: 50)$ \\
\hline I & 3,03 & 3,63 & 3,63 \\
II & 3,63 & 3,3 & 3,5 \\
III & 3,43 & 3,57 & 2,17 \\
\hline$\Sigma$ & 10,09 & 10,5 & 9,3 \\
\hline$\Sigma$ & $3,37 \pm 0,77$ & $3,51 \pm 0,77$ & $3,43 \pm 0,58$ \\
\hline
\end{tabular}

Nilai rerata yang didapatkan, diketahui bahwa nilai rerata paling tinggi merupakan rerata produk PI (susu skim 20\% : tape ubi ungu 50\% : jamur kuping 30\%) dengan nilai rerata sebesar 3,51.

Hasil analisis menggunakan uji friedman rank terhadap parameter tekstur es krim tape ubi ungu dan jamur kuping didapatkan nilai sig $=0,04<\alpha=0,05$ maka $\mathrm{H}_{0}$ ditolak yang berarti proporsi penambahan tape ubi ungu dan jamur kuping berpengaruh terhadap tekstur yang dihasilkan. Sedangkan untuk persentase daya terima panelis terhadap produk tersaji dalam gambar 5 .

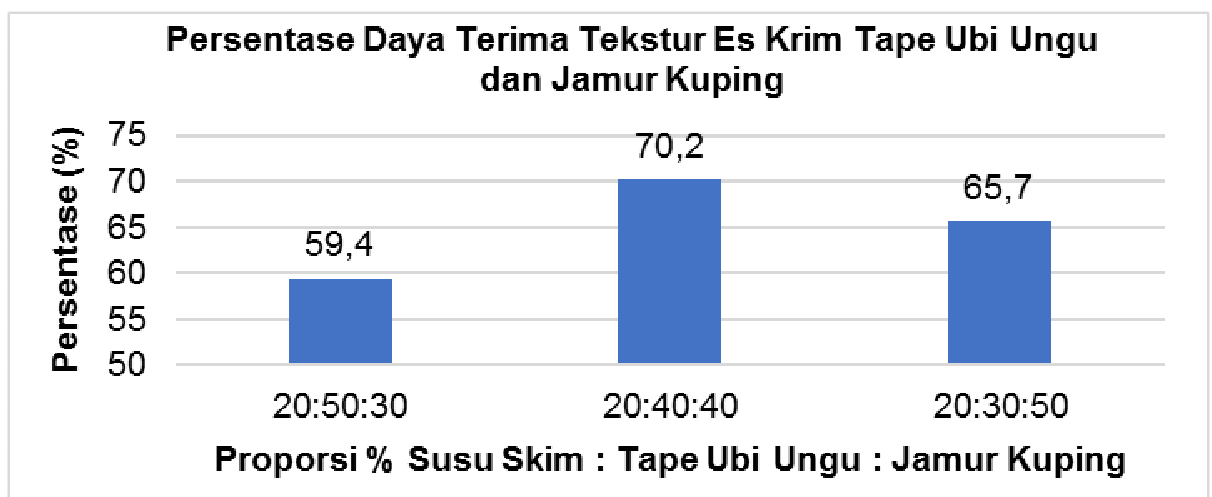

Gambar 5. Persentase daya terima panelis terhadap tekstur es krim tape ubi ungu dan jamur kuping 
Aspek penilaian tekstur pada PI (susu skim 20\% : tape ubi ungu 50\% : jamur kuping 30\%) menghasilkan persentase $59,4 \%$ dengan tekstur produk lebih lunak karena tekstur tape ubi ungu lembek sehingga apabila proporsi yang ditambahkan lebih banyak maka menghasilkan es krim dengan tekstur lebih lunak. Sedangkan pada PII (susu skim 20\% : tape ubi ungu 40\% : jamur kuping 40\%) menghasilkan nilai persentase $70,2 \%$ dengan tekstur yang lebih disukai oleh panelis yaitu tidak terlalu padat dan tidak terlalu lunak. Pada PIII (susu skim 20\% : tape ubi ungu 30\% : jamur kuping $50 \%$ ) menghasilkan persentase $65,7 \%$ dengan tekstur produk lebih padat karena proporsi penambahan jamur kuping lebih banyak sehingga menghasilkan tekstur yang dominan jamur kuping daripada tape ubi ungu. Dari ketiga perlakuan panelis cenderung lebih menyukai produk PII (susu skim 20\% : tape ubi ungu 40\% : jamur kuping 40\%), hal ini dikarenakan penambahan tape ubi ungu dan jamur kuping dengan proporsi yang sama menghasilkan tekstur yang pas yaitu dominan pada masingmasing bahan, tidak terlalu lunak dan tidak terlalu padat. Semakin tidak dominan penambahan tape ubi ungu dan jamur kuping pada es krim, daya terima panelis semakin menurun terhadap parameter tekstur. Menurut penelitian Filiyanti, dkk (2013), tekstur merupakan komponen yang penting dari es krim, hal ini berkaitan dengan jumlah padatan yang ditambahkan. Semakin banyak penambahan padatan maka akan mempengaruhi tekstur dari es krim.

\section{Overrun}

Nilai rerata yang didapatkan, diketahui bahwa nilai rerata paling tinggi merupakan rerata produk PI (susu skim 20\% : tape ubi ungu 50\% : jamur kuping 30\%) dengan nilai rerata sebesar 26,78.

Hasil uji statistik oneway anova overrun tape ubi ungu dan jamur kuping didapatkan nilai sig $=0,006<\alpha=0,01$ maka $\mathrm{H}_{0}$ ditolak yang berarti proporsi penambahan tape ubi ungu dan jamur kuping berpengaruh terhadap overrun es krim. Kemudian dilanjutkan dengan uji Duncan dan didapatkan hasil adanya kesamaan notasi antara produk dengan perlakuan PI (susu skim 20\% : tape ubi ungu 50\% : jamur kuping 30\%) dan PIII (susu skim 20\% : tape ubi ungu 30\% : jamur kuping 50\%). Sedangkan untuk persentase overrun terhadap produk tersaji dalam gambar 6 .

Tabel 5. Rerata Overrun es krim tape ubi ungu dan jamur kuping

\begin{tabular}{cccc}
\hline & \multicolumn{3}{c}{ Perlakuan Produk } \\
\cline { 2 - 4 } Replikasi & \multicolumn{3}{c}{ Susu Skim $(\%):$ Tape Ubi Ungu $(\%):$ Jamur Kuping(\%) } \\
\cline { 2 - 4 } & PI & PII & PIII \\
& $(20: 50: 30)$ & $(20: 40: 40)$ & $(20: 30: 50)$ \\
\hline I & 26,78 & 21,67 & 24,14 \\
II & 26,78 & 21,67 & 26,67 \\
III & 26,78 & 23,3 & 27,59 \\
\hline$\Sigma$ & 80,34 & 66,64 & 78,4 \\
\hline$\Sigma$ & $26,78 \pm 0,00$ & $22,21 \pm 0,54$ & $26,13 \pm 1,79$ \\
\hline Notasi & $\mathrm{B}$ & $\mathrm{A}$ & $\mathrm{B}$ \\
\hline
\end{tabular}

Ket : notasi yang berbeda menunjukkan perbedaan overrun berdasar uji Duncan pada $\alpha=$ 0,05 


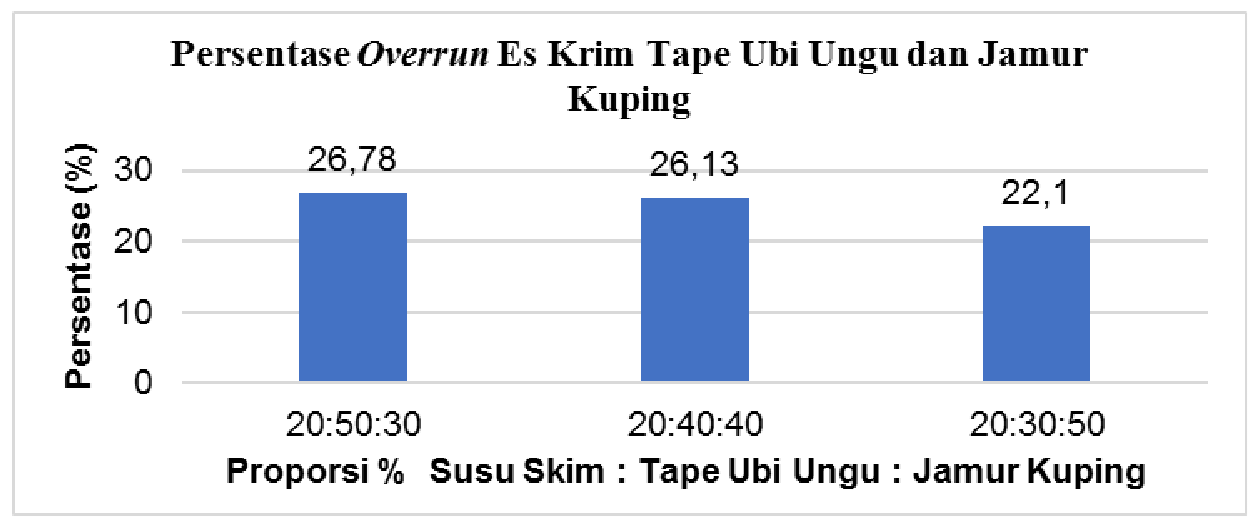

Gambar 6. Persentase Overrun es krim tape ubi ungu dan jamur kuping

Berdasarkan uji overrun, PI (susu skim 20\% : tape ubi ungu 50\% : jamur kuping $30 \%$ ) diperoleh hasil persentase tertinggi dari ketiga perlakuan yaitu $26,78 \%$. PII (susu skim $20 \%$ : tape ubi ungu $40 \%$ : jamur kuping 40\%) diperoleh hasil persentase lebih sedikit dibawahnya yaitu $26,13 \%$. PIII (susu skim 20\% : tape ubi ungu 30\% : jamur kuping 50\%) diperoleh hasil persentase terendah yaitu $22,1 \%$. Hasil overrun es krim tape ubi ungu dan jamur kuping pada ketiga perlakuan belum memenuhi standar overrun es krim yang baik. Es krim berkualitas baik memiliki overrun untuk skala rumah tangga berkisar 35-50\%, sedangkan untuk skala industry $70-80 \%$. Rendahnya overrun pada es krim dikarenakan sedikitnya udara yang terperangkap ke dalam es krim selama agitasi (Padaga dan Sawitri, 2005). Ada beberapa faktor yang dapat meningkatkan persentase overrun adalah penambahan kuning telur, suhu yang cukup dan alat pembeku yang baik (Achmad, 2012).

Penambahan tape ubi ungu dan jamur kuping meningkatkan padatan dalam adonan semakin besar sehingga adonan semakin kental. Jamur kuping mengandung serat sebanyak $21,97 \%$ per $100 \mathrm{~g}$ jamur kuping, serat memiliki kemampuan mengikat air dalam adonan es krim. Selain itu pada ubi jalar ungu mengandung amilopektin. Amilopektin memiliki gugus hidroksil yang bersifat hidrofilik sehingga dapat menyerap molekul air yang dapat mempengaruhi kekentalan adonan es krim, hal ini dikarenakan amilopektin dan serat menyebabkan sempitnya ruang antara partikel. Kekentalan yang tinggi akan semakin membatasi mobilitas molekul air karena ruang antar partikel menyebabkan udara yang masuk selama agitasi semakin sedikit sehingga nilai overrun yang dihasilkan semakin rendah. Es krim pada PIII dengan proporsi tape ubi ungu 30\% dan jamur kuping $50 \%$ memiliki tingkat overrun yang sangat rendah karena jamur kuping dengan proporsi yang banyak dapat mengikat air lebih banyak pada adonan. Pada hasil presentase overrun PI dengan proporsi tape ubi ungu 50\% dan jamur kuping 30\% serta PII dengan proporsi tape ubi ungu $40 \%$ dan jamur kuping $40 \%$ memiliki perbedaan yang tidak terlalu signifikan. 


\section{Titik Leleh}

Tabel 6. Rerata Titik Leleh Es Krim Tape Ubi Ungu dan Jamur Kuping

\begin{tabular}{cccc}
\hline & \multicolumn{3}{c}{ Perlakuan Produk } \\
\cline { 2 - 4 } Replikasi & \multicolumn{3}{c}{ Susu Skim $(\%):$ Tape Ubi Ungu (\%) : Jamur Kuping(\%) } \\
\cline { 2 - 4 } & PI & PII & PIII \\
& $(20: 50: 30)$ & $(20: 40: 40)$ & $(20: 30: 50)$ \\
\hline I & 55 & 59 & 63 \\
II & 56 & 56 & 65 \\
III & 55 & 54 & 68 \\
\hline$\Sigma$ & 166 & 169 & 196 \\
\hline$\Sigma$ & $55,3 \pm 0,58$ & $56,3 \pm 2,89$ & $65,3 \pm 2,51$ \\
\hline Notasi & $\mathrm{A}$ & $\mathrm{A}$ & $\mathrm{B}$
\end{tabular}

Ket : notasi yang berbeda menunjukkan perbedaan overrun berdasar uji Duncan pada $\alpha=$ 0,05

Nilai rerata yang didapatkan, diketahui bahwa nilai rerata paling tinggi merupakan rerata produk dengan PIII (susu skim 20\%: tape ubi ungu 30\% : jamur kuping 50\%) dengan nilai rerata sebesar 65,3 menit.

Berdasarkan hasil uji statistik oneway anova overrun tape ubi ungu dan jamur kuping didapatkan nilai sig $=0,004<\alpha=$ 0,01 maka H0 ditolak yang berarti proporsi penambahan tape ubi ungu dan jamur kuping berpengaruh terhadap titik leleh es krim. Kemudian dilanjutkan dengan uji Duncan dan didapatkan hasil adanya kesamaan notasi antara produk dengan PI (susu skim 20\% : tape ubi ungu 50\% : jamur kuping 30\%) dan PIII (susu skim 20\% : tape ubi ungu 50\%: jamur kuping 30\%). Sedangkan untuk persentase daya terima panelis terhadap produk tersaji dalam gambar 7 .

Uji titik leleh terhadap es krim tape ubi ungu dan jamur kuping didapatkan hasil pada PI (susu skim 20\% : tape ubi ungu 50\% : jamur kuping 30\%) dengan waktu leleh paling sedikit dari kedua perlakuan yang lain yaitu selama 55,3 menit. Pada PII (susu skim 20\% : tape ubi ungu 40\% : jamur kuping $40 \%$ ) tidak jauh berbeda yaitu 56,3 menit.
Pada PIII (susu skim 20\% : tape ubi ungu $30 \%$ : jamur kuping 50\%) memperoleh hasil uji titik leleh yaitu selama 65,3 menit. Dari ketiga perlakuan, es krim yang memiliki waktu leleh paling lama yaitu es krim pada PIII (susu skim 20\% : tape ubi ungu 30\%: jamur kuping 50\%) dengan penambahan tape ubi ungu 30\% dan jamur kuping 50\% dengan hasil persentase 65,3 menit. Hal ini dikarenakan penambahan jamur kuping yang mengandung tinggi serat sebesar $21,97 \%$ per $100 \mathrm{~g}$ dengan proporsi $50 \%$ dipadukan dengan tape ubi ungu dengan proporsi $30 \%$. Serat pada jamur kuping dan amilopektin pada tape ubi ungu dapat mengikat air dalam adonan es krim lebih banyak sehingga kristal es yang terbentuk tidak cepat meleleh. Selain itu titik leleh dipengaruhi oleh susunan trigliserida lemak "whipping cream" yang mengandung asam lemak tidak jenuh, pada suhu ruang asam lemak ini akan berwujud cair sehingga hal tersebut berpengaruh pada titik leleh es krim (Masykuri, 2012). Pada penelitian Kurnia dan Yunianta (2014), es krim yang baik mempunyai kecepatan meleleh antara 20-30 menit/100 g es krim pada suhu kamar 


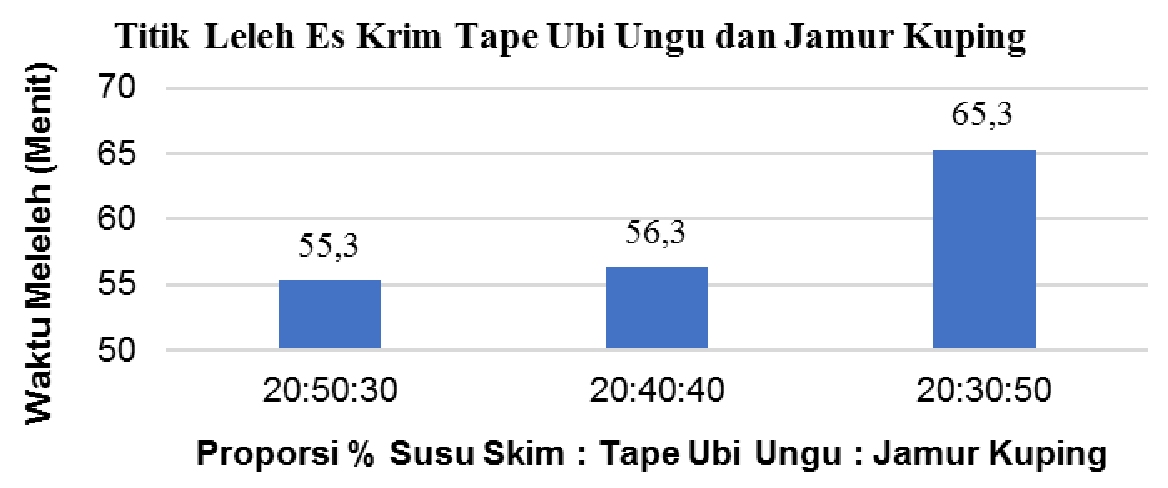

Gambar 7. Titik leleh es krim tape ubi ungu dan jamur kuping

\section{KESIMPULAN DAN SARAN}

\section{Kesimpulan}

1. Hasil persentase daya terima warna, PIII merupakan perlakuan dengan hasil persentase tertinggi. Sedangkan aroma, rasa dan tekstur PII (susu skim 20\% : tape ubi ungu 40\% : jamur kuping 40\%) adalah perlakuan dengan hasil persentase tertinggi.

2. Ada pengaruh penambahan tape ubi ungu dan jamur kuping terhadap overrun es krim.

3. Ada pengaruh penambahan tape ubi ungu dan jamur kuping terhadap titik leleh es krim.

\section{Saran}

Achmad, F. Nurwantoro dan S. Mulyani. (2012). Daya kembang, total padatan, waktu pelelehan dan kesukaan es krim fermentasi menggunakan starter. Animal Agriculture Journal. Vol. 1 (2).

Asnawi, Muhammad, Sumardi Hadi Sumarlan dan Mochamad Bagus Hermanto. (2013). Karakteristik tape ubi kayu (Manihot utilissima) melalui proses pematangan dengan penggunaan pengontrol suhu. Jurnal Bioproses Komoditas Tropis, Vol. 1 (2).
1. Perlu dilanjut dengan pengujian umur simpan dan metode pengemasan es krim.

2. Perlu adanya perbaikan proporsi tape ubi ungu dan jamur kuping agar daya terima meningkat serta overrun dan titik leleh es krim sesuai dengan standart yang ditentukan.

3. Perlu adanya perbaikan metode pembuatan es krim yaitu menggunakan Ice Cream Maker agar kualitas es krim meningkat.

4. Perlu penelitian lebih lanjut terkait pengujian zat gizi makro dan mikro pada es krim tape ubi ungu dan jamur kuping.

\section{DAFTAR PUSTAKA}

Filiyanti, Ita, Dian Rachmanawati Affandi dan Bambang Sigit Amanto. 2013. Kajian penggunaan susu tempe dan ubi jalar ungu sebagai pengganti susu skim pada pembuatan es krim nabati berbahan dasar santan kelapa. Jurnal Teknologi Pangan 2 (2):2302-0733.

Husna, el Nida, Melly Novita dan Syarifah Royana. 2013. Kandungan antosianin dan aktivitas antioksidan ubi jalar ungu segar dan produk olahannya. Jurnal Teknologi Pangan 33 (3):2680-5194

Kurnia, Rizky dan Yunianta. 2014. Pembuatan Es Krim Tempe - Jahe 
(Kajian Proporsi Bahan dan Penstabil Terhadap Sifat Fisik, Kimia, dan Organoleptik). Universitas Brawijaya. Malang.

Masykuri, Pramono dan D. Ardila. (2012). Resistensi Pelelehan, Overrun, dan Tingkat Kesukaan Es Krim Vanilla yang Terbuat dari Bahan Utama Kombinasi Krim Susu dan Santan Kelapa. Jurnal Aplikasi Teknologi Pangan, Vol. 1 (3).

Murtiningsih dan Suyanti. 2011. Pemanfaatan Tepung Ubi Ungu dalam Pembuatan Produk
Pasteurisasi. Universitas Negeri Yogyakarta. Yogyakarta.

Padaga, M dan Manik E. Sawitri. 2005. Membuat Es Krim yang Sehat. Trubus Agrisarana. Surabaya.

Purnomowati. 2015. Biologi Jamur Kuping (Auricularia auricula). Universitas Jendral Soedirman. Purwokerto.

Tjokrokusumo, Donowati. (2015). Diversitas Jamur Pangan Berdasarkan Kandungan Beta-glukan dan Manfaatnya terhadap Kesehatan. PROS SEM NAS MASY BIODIV INDON. Vol.1 (6): 2407-8050. 